\title{
Los difíciles orígenes de la Universidad de Barcelona (1401-1559)
}

\author{
The difficult Origins of the University of Barcelona (1401-1559)
}

\author{
ANTONIO FERnÁndeZ LuZÓN \\ afluzon@gmail.com
}

Universitat Autònoma de Barcelona

Resum: La primera institución verdaderamente universitaria de Barcelona fue el Estudio General de Medicina fundado por el rey Martín I en 1401, al que al año siguiente añadió una facultad de Artes. Habría que esperar hasta 1559 para que el ayuntamiento llegara a un acuerdo con la universidad de los médicos y pusiera en práctica el antiguo privilegio que le otorgó Alfonso el Magnánimo, en 1450, para fundar un Estudio General con todas las facultades. Esta institución universitaria, financiada y gobernada por el municipio, se convirtió rápidamente en un avanzado centro de saber con una gran proyección cultural y política en la Cataluña moderna.

Palabras clave: Universidad, Estudio General, humanismo, artes liberales

Abstract: The first truly university institution in Barcelona was the medical Studium Generale, founded by Martin I in 1401. The next year an arts faculty was added. It was necessary to wait until 1559 for the town hall to reach an agreement with the medical faculty to put into practice the old privilege granted by Alfonso the Magnanimous, who in 1450 founded a Estudio General with all faculties. This university institution, funded and governed by the municipality, quickly became an advanced center of knowledge with a great cultural and political projection in modern Catalonia.

Keywords: University, Estudio General, humanism, liberal arts 


\section{Introducción}

La universidad, tal y como la conocemos hoy, fue una creación específica de la Europa medieval. Ni la civilización clásica, Bizancio, el Islam o la China tuvieron instituciones semejantes (RidderSymoens 1994:42). A las universidades se las denominaba entonces Estudios Generales, que podían ser generales o particulares. Los Estudios Generales eran los fundados por el papa, emperador o rey, podían otorgar grados de validez universal y debían tener, además de la facultad de Artes, otra superior de Derecho, Teología o Medicina. Los Estudios particulares, en cambio, no cumplían estos requisitos y solían depender de un municipio, catedral u orden religiosa (Álvarez de Morales 1987: 57-65).

La Corona de Aragón pasó a ser uno de los primeros conjuntos políticos europeos que dispusieron de universidad -y de una de justo renombre, dada la calidad de sus saberes-cuando Jaime I incorporó por herencia materna a sus estados la ciudad de Montpellier, donde se venían impartiendo desde tiempo atrás estudios de derecho y medicina que gozaban de gran prestigio. Después de su paso al dominio francés, Montpellier continuó constituyendo un importante foco de atracción para los estudiantes catalanes hasta que, en la segunda mitad del siglo xvI, las turbaciones causadas por las guerras de religión y las pragmáticas de Felipe II prohibiendo estudiar en el extranjero (1559 para Castilla y 1568 para la Corona de Aragón) cortaron temporalmente esta peregrinación académica. ${ }^{1}$

La larga gestación de la universidad de Barcelona patentiza las diferentes expectativas de la Corona y de la municipalidad ante la institución universitaria. Los reyes querían asociar los centros de enseñanza superior a sus políticas territoriales, creando al principio una universidad para cada reino y demandando su colaboración para el establecimiento y consolidación de las instituciones gubernamentales con que pretendían dominar a las aristocracias campesinas y las oligarquías urbanas. Los municipios necesitaban médicos y abogados, a los que exigían pasar unos exámenes y concedían la oportuna licencia para ejercer sus profesiones. ${ }^{2}$ Así lo establecieron, en la Corona de Aragón, las Cortes de 1289 y 1359. En Barcelona, la concesión de la licentia utendi, en el caso de los médicos no cristianos, valía tanto como un título universitario e implicaba un reconocimiento de la valía de los médicos judíos, expertos oculistas (cristallers o mestres de ulleres) y fabricantes de vidrios correctores que se vendían en el extranjero (Carrere 1967: 382-383).

\section{Barcelona rechaza la universidad de Martín el Humano}

El alto coste económico, los privilegios de estudiantes y maestros (fuero especial, exención de impuestos y tasas, fijación de alquileres máximos) y el temor a la conflictividad estudiantil explicarían la aparición entre la clase dirigente barcelonesa de una corriente de opinión contraria a la creación

1 Batlle i Prats (1947) y, sobre todo, Dulieu (1971).

2 Véase, para los juristas, Valls Taberner (1954).

SCRIPTA, Revista internacional de literatura i cultura medieval i moderna, núm. 15 / juny 2020 / pp. 172 - 186 ISSN: 2340-4841 · doi:/ SCRIPTA.15.17567 
de la universidad. Una oposición que el conocimiento de las dificultades que atravesaba el Estudio ilerdense no hizo sino reafirmar. Sería, no obstante, erróneo creer que el recelo de las clases dirigentes urbanas implicaba un rechazo al saber en general. Lo que no querían era una institución privilegiada como la universitaria, que limitara su autoridad en el ámbito urbano y supusiera un dispendio excesivo para las arcas municipales.

El ayuntamiento consideraba suficiente el dispositivo educativo existente en la ciudad, que contaba con importantes escuelas catedralicias, municipales y privadas, aunque quienes quisieran obtener los grados universitarios tuvieran que desplazarse a Lérida o a Montpellier. Las órdenes religiosas también disponían de Estudios particulares, dedicados fundamentalmente a la enseñanza de la teología. En el Estudio de los dominicos, al que el rey Jaime II asignó una renta anual de 12.000 sous en 1297, además de artes y teología, se impartieron también lecciones de derecho y nociones de medicina.

No ha de sorprender, por tanto, que en 1346 el Consejo de Ciento se negara a que fuese publicado un pregón anunciando los cursos de Lleida porque «desde tiempo inmemorial se enseñaban en Barcelona gramática y lógica, derecho, medicina y filosofía». ${ }^{3} \mathrm{Ni}$ que en 1377 , ante las dificultades económicas que atravesaba el Estudio de Lérida y se propusiera trasladarlo a Barcelona, el Consejo de Ciento rechazara la oferta por considerar que atentaría contra sus prerrogativas y que la conflictiva población estudiantil representaría un peligro para la paz y tranquilidad de la ciudad. Por su parte, el rey Pedro IV el Ceremonioso escribió al papa Gregorio XI para que no accediera al traslado del centro ilerdense, alegando que la ciudad de Barcelona tenía tantos privilegios que no necesitaba el Estudio General.

En 1398, roto ya el monopolio ilerdense de exclusividad docente por la fundación de los Estudios Generales de Perpiñán (1349) y Huesca (1354), el rey Martín el Humano quiso fundar un Estudio General con todas las facultades en Barcelona, pero la ciudad rechazó el ofrecimiento diciendo que eran más los «peligros y escándalos» que los beneficios que se podían derivar (Balari i Jubany: 12-17). Claude Carrère (1979) explicó la desafección de Barcelona hacia la universidad porque ésta no se adaptaba a las necesidades culturales de la urbe, más interesada en la enseñanza de las matemáticas aplicadas, la cartografía y la jurisprudencia marítima y mercantil, que en un estéril saber escolástico que había dejado de ser un factor de progreso y fermentación intelectual. Más allá del interés por los conocimientos prácticos a que alude Carrère, no incompatibles con los que se impartían en las instituciones universitarias, el ayuntamiento barcelonés debió tener muy presente que los monarcas solían conceder el privilegio fundacional de las universidades, pero trasladaban la responsabilidad de financiar estas costosas instituciones a los municipios, que generalmente carecían de rentas suficientes para garantizar su eficaz funcionamiento, como demostraba a todas luces el caso de Lérida (Gaya Massot 1952).

3 Documentos, pp. 32-33. 
Pese a la negativa municipal y sin contar aún con la aprobación pontificia, el rey Martín I -para preservar la salud pública, la de su persona ya que se proponía residir en Barcelona y, sobre todo la de su nieto bastardo Fadrique de Luna, al que pretendía hacer heredero- fundó en 1401 un Estudio General de Medicina con los mismos privilegios que el de Montpellier, ampliado al año siguiente con una facultad de Artes, aunque sin autorización pontificia. El Estudio de Medicina del rey Martín, como el de Montpellier, era una «universidad de maestros» con potestad para promulgar estatutos y elegir al Canciller y Rector. La autonomía concedida a la corporación universitaria por aquel monarca culto, protector e impulsor de los estudios, no fue recibida de buen grado por los magistrados municipales, que se mostraron reticentes a aceptarla por considerar que lesionaba su derecho a organizar con total independencia los estudios superiores.

El 6 de octubre de 1401, la ciudad utilizó su influencia para conseguir que dos de los catedráticos más prestigiosos del Estudio de Medicina, Antoni Ricart y Pere de Coll, se comprometieran a enseñar medicina, filosofía y astrología bajo la autoridad de los consellers y a no invocar contra las decisiones de éstos ningún privilegio pontificio o real. La oposición de un grupo de médicos de la ciudad logró que, el 31 de octubre de 1401, los recién nombrados maestros del Estudio estuvieran a punto de dejar la enseñanza y el rey tuvo que conminarles a continuar en sus puestos diciendo que no pensaba consentir que se destruyese lo por él fundado.

En 1408, volvió Martín el Humano a insistir en su idea de fundar en Barcelona un Estudio General con todas las facultades. Aunque en esta ocasión se suscitó un vivo debate y un sector de la clase dirigente se manifestó partidario de la propuesta, el Consejo de Ciento volvió a rechazarla con mayor rotundidad, si cabe, que diez años antes:

\begin{abstract}
Acordà lo dit Consell que per moltes rahons en lo dit consell plenerament discutides, Estudi General ne altre més avant que vuy se té en Barchinona no és bo ne profitós a la ciutat. E més avant ordonà lo dit Consell que per tal car moltes vegades lo dit Estudi és estat profert a la ciutat, e alguns hy fan lur poder que la ciutat l'acceptàs, e per açò's sien tenguts diverses Consells de Cent jurats en los quals tostemps és estat denegat, que d'aquí avant si tal offerta se fa, sia denegada sens que no'n calla tenir Consell de Cent jurats. ${ }^{4}$
\end{abstract}

\title{
2. E1 privilegio de Alfonso el Magnánimo
}

A mediados del siglo xv, la grave crisis económica hizo que la oligarquía barcelonesa cambiara de parecer y considerara que la creación de la universidad sería beneficiosa para la ciudad. En la reunión del Consejo de Ciento, celebrada el 29 de febrero de 1448, se sometió a deliberación una propuesta para erigir un Estudio General, argumentando que «en aquesta ciutat són totes coses pertanyents a ciutat insigna e notable, sinò que ych fall Studi general, qui l'ennobliria molt e los fills dels ciutadans

4 Documentos, pp 42-143 
haurien ocassió d'acquirir sciència e a la dita ciutat ne reportaria gran profit e fama». ${ }^{5}$ En el mes de abril de 1450, la ciudad envió al jurista Guillem Jordà a informarse de cómo funcionaba el Estudio de Perpiñán. En su dictamen, Jordà recomendaba solicitar al rey y al papa sendas provisiones para fundar un Estudio general de teología, cánones y leyes (perquè de medecina e arts ja n’i ha), e insistía en que el Rector careciera de jurisdicción y los estudiantes de fuero particular. De esta forma, según Jordà, la universidad dependería del Consejo de Ciento y del capítulo catedralicio, que se encargarían de aprobar las normas que regularan su organización y funcionamiento.

El privilegio concedido el 3 de septiembre de 1450 por el rey Alfonso el Magnánimo, basado en el memorial que le presentaron los embajadores de la ciudad, concedía a los consellers licencia y facultad para «estatuir, fundar y ordenar un Estudio General de teología, derecho canónico y civil, filosofía moral y natural, siete artes liberales, medicina y cualesquiera otras ciencias y doctrinas», con los mismos privilegios de Lérida y Perpiñán (Sanabre 1960). El 30 de septiembre, a petición del rey y de la ciudad, el papa Nicolás V expedía la bula fundacional del Estudio General, comunicándole todos los privilegios, exenciones, inmunidades, libertades y honores que tenían los maestros y estudiantes de la Universidad de Toulouse. ${ }^{6}$

La diferencia entre ambas cartas fundacionales es fundamental. Mientras que en la bula de Nicolás $\mathrm{V}$ es el papa quien funda el Estudio, el privilegio real no erigía la universidad sino que autorizaba a la ciudad a crearla cuando lo considerara oportuno. Sobre esta potestad, el ayuntamiento barcelonés fundaría el Estudio General, un siglo después, asumiendo el papel de suprema autoridad universitaria. En este sentido, el privilegio de Alfonso Magnánimo señaló el punto de inflexión hacia el abierto intervencionismo de las autoridades municipales, que dedicaron un considerable esfuerzo argumentativo a demostrar su derecho de patronazgo sobre el Estudio General, aunque todavía en el siglo XVII el tema seguía siendo objeto de debate. La amplia discrecionalidad que Alfonso $\mathrm{V}$ concedió a los consellers para fundar y organizar la universidad fue esgrimida por la ciudad para fundamentar su derecho a controlar la institución docente, al margen de cualquier injerencia externa. Paralelamente, el municipio barcelonés ignoró o tergiversó, según su conveniencia, el privilegio de Martín el Humano, contrario a sus intereses, pues el monarca había otorgado plena autonomía a la corporación universitaria por él fundada, concediéndole la facultad de hacer estatutos y nombrar a las autoridades académicas.

Después de conseguir la autorización real, Barcelona no fue capaz de erigir la universidad, cuya puesta en funcionamiento se demoraría hasta 1559. ¿Por qué se retrasó la fundación de la universidad? Según Gaya Massot (1952), la causa principal fue la oposición de la universidad de Lérida, que, utilizando la influencia del cardenal Antoni Cerdà en Roma, consiguió el 19 de noviembre de 1450 que el papa Nicolás V suspendiera la bula concedida apenas dos meses antes al Estudio barcelonés. Esta anulación,

5 Documentos, p. 244.

6 Documentos, pp. 255-256.

SCRIPTA, Revista internacional de literatura i cultura medieval i moderna, núm. 15 / juny 2020 / pp. 172 - 186 ISSN: 2340-4841 · doi:/ SCRIPTA.15.17567 
que los consellers de Barcelona ignoraron por razones obvias, no invalidaba la concesión real, aunque sí debió hacerles ver la inconveniencia de fundar la universidad sin contar con la aprobación pontificia, la única capaz de dar a sus títulos validez universal. La hipótesis más plausible del retraso debió ser la falta de recursos económicos para financiarla. Sea como fuere, el gobierno municipal entró en una fase de dilaciones y dio largas al asunto hasta que el estallido de la guerra civil (1462-1472), durante el reinado de Juan II, acabó relegando la cuestión universitaria a un segundo plano.

En 1484, el municipio volvió a tratar sobre la necesidad de fundar el Estudio General y, tres años después, solicitó con nulo éxito a Fernando el Católico la confirmación del privilegio de 1450, afirmando que si antes no lo habían puesto en práctica era porque no disponían de los maestros necesarios. ${ }^{7}$ En lugar de atender la petición del Consejo de Ciento, Fernando el Católico refrendó el 14 de enero de 1488 el privilegio del Estudio de Medicina, confirmando todas sus prerrogativas y haciéndole extensivas también las de Lérida. Además, el monarca ordenó la reunión de todas las escuelas de artes de la ciudad en un solo centro dirigido por el canciller del Estudio de Medicina, al que reconocía también el derecho a intervenir en los exámenes y en el control del ejercicio profesional de cirujanos y boticarios.

Pocos días más tarde, el rey no tuvo reparo en contravenir lo por él ordenado y el 25 del mismo mes y año confirmó el privilegio concedido al maestro Aleix Bambaser por Juan II, en 1477, para el establecimiento de un Estudio de artes liberales y otras ciencias en Barcelona (Balari i Jovany 1897). El ayuntamiento no se opuso al privilegio de Aleix Bambaser, pero sí al otorgado al Estudio de Medicina cuya derogación solicitó en carta dirigida a Fernando el Católico en 1491. Los munícipes argumentaban que no correspondía a los médicos organizar la universidad, sino a la ciudad en virtud del privilegio de Alfonso el Magnánimo que aún no habían ejecutado, pero que pensaban llevar pronto a la práctica. No obstante, Fernando el Católico continuó respaldando al Estudio de Medicina y ordenó que se cumpliese lo dispuesto en 1488 mediante una ejecutoria del 25 de septiembre de 1495.

\section{E1 Estudio de las Artes liberales (1507-1559)}

En 1500, apoyándose en la ejecutoria de 1495, el canciller del Estudio de Medicina reclamó que se cerrasen las nuevas escuelas de artes, no sometidas a su autoridad, que se habían abierto en la ciudad, y, cuatro años después el lugarteniente general del rey, conde de Ribagorza, volvió a insistir en la estricta observancia del privilegio de 1488. La firmeza del poder monárquico acabó doblegando la resistencia de la ciudad que, el 29 de noviembre de 1507, promulgaba unas ordenanzas prohibiendo las escuelas privadas y ordenando la unificación de todas las escuelas de artes (incluidas las Escuelas Mayores de la ciudad) en el Studi de les arts liberals, que, según lo establecido en el privilegio de 1488, estaría presidido por el canciller del Estudio de Medicina:

7 Documentos, pp. 272-273. 


\begin{abstract}
que com, de algun temps ençà, lo Studi qui antigament era en la dita ciutat de les arts liberals sia vengut a gran disminució, així per multiplicació de scoles que per diverses persones són stades introduïdes en diverses parts de la dita ciutat(...), com encara per insuficiència dels qui han volgudes introduir dites scoles, per tant, los honorables consellers e prohòmens de la dita ciutat ordenaren que de qui avant les dites scoles de dites arts liberals sien reduïdes y tornades a unes soles scoles, en les quals lo Canceller de dit Studi y de Medicina presideix, tollents y abolints totes altres scoles qui sien stades introduides en la dita ciutat de les dites artes liberals.
\end{abstract}

Aunque los consellers de Barcelona se habían arrogado la facultad de legislar sobre el funcionamiento del Estudio de las artes liberales, el precario equilibrio de poderes que establecían las ordenanzas de 1507 se evidencia tanto en la ambigua denominación (Studi de les arts liberals, Scoles majors o Studi major) como en el establecimiento de una doble jerarquía de gobierno. Por un lado, los maestros de artes, el síndico, notario y oficiales quedaban sometidos a la autoridad directa del Canciller de medicina. Por otro, el maestro del acento de la catedral -que había regido hasta entonces las Escuelas Mayores- conservó el control de la enseñanza gramatical. ${ }^{9}$

Para financiar el pago de los maestros y el alquiler de los locales donde se impartían las clases, el 25 de abril de 1508 el ayuntamiento de Barcelona decidió dotar al Estudio de Artes con una asignación fija de 120 libras anuales, procedentes de un impuesto municipal sobre la harina:

\begin{abstract}
perquè los emoluments de dites scoles no basten a la sustentatió de mestres, batxellers e altres qui acostumen legir en aquelles als fills dels ciutadans e poblats en dita ciutat, lo que redunde en grandíssim deservey de nostre Senyor Déu per la ignorància del oïnts en les dites scoles e grandíssim damnatatge de aquelles.(...), que per conservació del Studi de les arts liberals de la dita ciutat y dels mestres y batxellers de aquell, fossen assignats y consignats per la dita ciutat alguns salaris fins en summa de Cent y vint lliures. ${ }^{10}$
\end{abstract}

Las nuevas ordenanzas del 8 de octubre de 1508 establecieron que de las 120 libras asignadas por el municipio, 98 debían ser destinadas a pagar los salarios del profesorado y 22 al alquiler de los locales donde se impartían las clases. ${ }^{11}$ La financiación municipal se complementaba con los recursos aportados por los estudiantes, que consistían en el pago del bancaje (cuota por el uso de bancos y sillas) y la colecta (estipendio que recibía el maestro de los alumnos). Según el nuevo organigrama de gobierno, correspondía al Canciller la concesión de grados; al Rector, la vigilancia del orden, de

\footnotetext{
8 AHCB, Registre de crides i ordinacions, IV-12, p. 167.

9 AHCB, Registre de crides i ordinacions, p. 169.

10 AHCB, Registre de deliberacions, II-39, p. 44-45.

11 AHCB, Registre de crides i ordinacions, p. 181.
}

SCRIPTA, Revista internacional de literatura i cultura medieval i moderna, núm. 15 / juny 2020 / pp. 172 - 186 
los catedráticos y sus lecciones; al tesorero, la recaudación de los ingresos; al síndico, la defensa de los privilegios y ordenanzas, y la tramitación de pleitos; al notario, dar fe y registrar los actos de la universidad, y, al bedel, convocar los consejos y otras cosas pertenecientes a su oficio. El ayuntamiento se reservaba el derecho de legislar sobre las obligaciones de los catedráticos y las materias de enseñanza, a la vez que intervenía de forma determinante en los nombramientos del profesorado.

Según las citadas ordenanzas, el Estudio de Artes se ubicaría en el lugar donde se acostumbraba a leer medicina y locales circunvecinos, probablemente en una torre de la Boquería donde tenía su sede el Estudio de Medicina. ${ }^{12}$ Las clases comenzaban el 18 de octubre, fiesta de San Lucas, prolongándose hasta finales de junio. Con el fin de aumentar el número de lecturas sin afrontar mayores gastos, los bachilleres que estuvieran preparando el acceso al grado de maestro o doctor en artes debían leer por espacio de dos años sin salario y tener al menos una sabatina anual. Al principio de curso, los catedráticos desarrollarían una "prelección» sobre la materia que iban a impartir con el fin de atraer alumnos a sus respectivas cátedras.

Como las disposiciones estatutarias de 1507 y 1508 establecieron una sólida plataforma para la expansión de los estudios, la nueva situación no podía dejar de inquietar a la Universidad de Lérida, que pidió a Fernando el Católico que revocara el privilegio concedido al Estudio de Medicina y Artes de Barcelona. El monarca se plegó a las exigencias de Lérida y, el 12 de julio de 1510, revocó la concesión hecha a Barcelona, alegando que el privilegio de 1488 había sido expedido inadvertidamente por su protonotario. Sin embargo, la retractación real no tuvo ninguna consecuencia práctica y el Consejo de Ciento continuó apostando por la permanencia del Estudio como si nada hubiese cambiado.

El 3 de octubre de 1533, respondiendo a las peticiones de Cosme Amiguet, síndico de la Universitat del Studi dels artistes e metges de Barcelona, Carlos V confirmaba en su totalidad el privilegio de su abuelo Fernando el Católico y restablecía el sistema de insaculación anual para los oficios de canciller, rector y tesorero. ${ }^{13}$ Este espaldarazo legal y la favorable predisposición del emperador estimularon al gobierno municipal a llevar a cabo el viejo proyecto de fundar una universidad completa. El 29 de noviembre de 1533 el Consell de la Vintiquatrena dio instrucciones a los síndicos de Cortes para que solicitasen al rey que se «reformara o hiciera un Estudio General» por medio de constitución, pacto de Corte o del modo que creyese oportuno. Considerando que su fundación redundaría en beneficio de la utilidad pública, y particularmente de la formación de los eclesiásticos en una época en que abundaban los errores doctrinales, la ciudad proponía que para su financiación se establecieran una prestación anual sobre los obispados, abadías y prioratos de Cataluña por valor de 750 ducados, para lo cual debía solicitarse la aprobación del Papa Clemente VII. ${ }^{14}$

12 AHCB, Estudi General, doc. 14.

13 AHPB, Liber Studii Generalis, legajo 304

14 AHCB, Deliberacions, II-52, p. 91v-92.

SCRIPTA, Revista internacional de literatura i cultura medieval i moderna, núm. 15 / juny 2020 / pp. 172 - 186 ISSN: 2340-4841 · doi:/ SCRIPTA.15.17567 
Pese a que estas gestiones no dieron resultado, el propósito de la ciudad era firme. El 8 de agosto de 1536, después de consultar con las jerarquías eclesiásticas y algunos notables de la ciudad, se decidió iniciar la construcción de una casa para el Estudio General en el tramo superior de la Rambla, que, por dicho motivo, con el tiempo recibiría el nombre de Rambla de los Estudios. ${ }^{15}$ El 10 de agosto de 1536, el Consejo de Ciento aceptaba la donación del mercader Joan Claret, que ofreció para «la fäbrica y sustentatió del dit Studi C lliures de renda quiscun any y D lliures de comptants y altres offertass. ${ }^{16}$ Joan Claret aparece citado en la Dialéctica (1540) del filósofo Rafael Mambla como protector de los estudios humanísticos y benefactor de la universidad.

El 17 de octubre se convocaba a todos los barceloneses para que al día siguiente, fiesta de San Lucas, asistieran a la colocación solemne de la primera piedra del nuevo edificio del Estudio General, que había de servir para «disipar la nube de la odiosa ignorancia del entendimiento de los pobladores y habitantes de la ciudad». ${ }^{17} \mathrm{El} 24$ de octubre, Martín Ibarra inauguraba el nuevo curso académico en el Saló de Cent con una lección de gramática y poesía y, dos días después, micer Gómiz iniciaba una lectura de leyes y cánones en la biblioteca del monasterio de los franciscanos.

Mientras se construía el nuevo edificio, la ciudad volvió a suplicar a Carlos V que dotara al Estudio con una pensión anual de cien ducados de oro sobre los arzobispados y obispados de Cataluña, y de cincuenta sobre las abadías cuyos ingresos superaran los seiscientos ducados anuales. Justificaba su petición afirmando que el Estudio General redundaría en gran beneficio para el Principado de Cataluña, y aun para toda la cristiandad, pues los hombres de ciencia que en él se formaran contribuirían a extirpar «las herejías que por nuestros pecados han pululado por el mundo» y a iluminar «a los cristianos con sus predicaciones y doctrinas». ${ }^{18}$

Carlos V, desde Monzón, escribió al papa solicitando su protección y ayuda para la construcción y sostenimiento del Estudio General:

\footnotetext{
El marqués de Aguilar, mi embajador, suplicará de mi parte a Vuestra Santidad algunas cosas en recomendación de la fábrica y sustentación de un Estudio General que se hace en la Ciudad de Barcelona, que será obra perpetua y costosa y muy útil a todos, especialmente a la gente pobre. Yo suplico a Vuestra Santidad que le dé fe y creencia y tenga por encomendada esta obra, según que allá más largamente lo entenderá del dicho Embajador, que en ello recibiré singular gracia (Oriol Montagut: 15).
}

15 AHCB, Registre de deliberacions, II-53, pp. 58-60.

16 Dietari, p. 46.

17 Ibid, p. 47.

18 AHCB, Estudi General, serie XVIII, vol. 9, doc. 17. 
El 27 de agosto de 1537 la ciudad volvió a pedir a las Cortes y al monarca ayuda económica para proseguir la construcción del edificio universitario y poder pagar a los maestros que en él leyeran. ${ }^{19}$ Todo fue en vano. Las obras del edificio universitario tuvieron que financiarse con aportaciones procedentes de las arcas municipales, que se complementaron con las contribuciones del cabildo catedralicio y de algunos particulares. En 1539, el Consejo de Ciento estableció un nuevo censal o título de deuda pública sobre el impuesto de la harina por importe de 550 libras para «proseguir y acabar la casa del Estudio». ${ }^{20}$ El edificio, de modestas proporciones, fue terminado en un tiempo récord y el día de San Lucas del año 1539 abría ya sus puertas para iniciar el nuevo curso luciendo el escudo imperial de Carlos V, que aún se conserva, en su fachada.

Los estatutos del Studi general novament edificat, promulgados el 4 de noviembre de 1539, ordenaron que todos los lectores y estudiantes se inscribieran en la matrícula, prohibiendo toda enseñanza fuera del Estudio, con excepción de las lecturas que los monasterios realizaban para los religiosos, bajo pena de cien sous. ${ }^{21}$ Como los estudios eran caros, los consellers rebajaron las tasas que pagaban los estudiantes, que no debía exceder en ningún caso de 18 sous. ${ }^{22}$ El reglamento de 1539 presenta la novedad de confiar la dirección del centro a un Primario nombrado por el gobierno municipal, mientras que el Canciller y Rector eran elegidos por los maestros en medicina y artes mediante el sistema de insaculación. El Primario, asistido por un consejo formado por representantes del cabildo catedralicio y de la ciudad, ordenaba todo lo concerniente al «buen regimiento del Estudio y utilidad de los estudiantes», examinaba la suficiencia de los lectores y velaba por el mantenimiento de la disciplina. También ejercía funciones de control ideológico, actuando como censor de los escritos y conclusiones. ${ }^{23} \mathrm{La}$ incorporación de la Iglesia a la dirección del Estudio puede explicarse, de un lado, por su contribución económica a los gastos de la institución, y de otro, porque su protección resultaba imprescindible en un momento en que arreciaba la persecución inquisitorial contra los erasmistas y luteranos (Fernández Luzón 2005: 42).

Para que se dieran algunas lecciones de derecho, el Consejo de Ciento ordenó, en 1541, que los abogados que quisieran optar al cargo de Prior de los Juristas tuvieran que haber impartido previamente, sin salario, una lección diaria de leyes o cánones durante un año en el Studi:

Per dar major favor al Studi general de la present Ciutat, y dar principi que en dit Studi hage algunes liçons de Leys y Cànones franquicies de salaris, y que sia causa que los juristes se exerciten en llur scièntia, statuïren e ordenaren los honorables consellers e prohòmens que de

19 AHCB, Registre de deliberacions, II-54, p. 35

20 AHCB, Registre de deliberacions, II-55, p. 18

21 AHCB, Registre de crides i ordinacions, IV-16, p. 23.

22 AHCB, Registre de crides i ordinacions, IV-16, p. 124.

23 AHCB, Estudi General, XVIII-9, doc. 20.

SCRIPTA, Revista internacional de literatura i cultura medieval i moderna, núm. 15 / juny 2020 / pp. 172 - 186 ISSN: 2340-4841 · doi:/ SCRIPTA.15.17567 
assí al davant ningun Juriste o doctor o licenciat en Cànones o Leys puga ésser elet en Prior dels Juristes, juxta forma del privilegi de la ciutat otorgat sobre dita electió, que primer no hage legit en lo dit Studi general, a hora còmmoda, una liçó un any de Leys o Cànones de la matèria o matèries que per los elets per lo Reverent Capítol y per la Ciutat de Barcelona per lo regiment de dit Studi los serà assignada. ${ }^{24}$

Después de muchos tratos y parlamentos con el obispo, cabildo y algunas personas amantes de las buenas letras, el 9 de octubre de 1544 los consellers sometieron a la aprobación del Consejo de Ciento unas nuevas ordenanzas, con las que esperaban solucionar los problemas hacendísticos y contratar «doctos catedráticos tanto en lengua latina como griega». ${ }^{25}$ Los nuevos estatutos consolidaron la participación de la Iglesia en el organigrama de gobierno e impulsaron los studia humanitatis mediante la creación de nuevas cátedras de filosofía, gramática, retórica y griego. A estos cambios se añadió, en 1547, la dotación por vez primera de una cátedra de teología, y, en 1551, de tres cátedras de medicina.

La declaración preliminar de las ordenanzas de 1544 entrevera las acostumbradas fórmulas retóricas sobre la trascendencia espiritual del conocimiento con la necesidad de formar a las clases dirigentes, además de insistir en que con la erección del nuevo Estudio General se evitarían los peligros y costes de estudiar en lugares lejanos, y la ciudad se beneficiara de la elevada afluencia de estudiantes:

\begin{abstract}
E per dita rahó, los honorables consellers y consell de la present ciutat hagen edificat novament, pochs anys ha, una casa o Studi prop lo portal de mossèn Sanct Sever, al cap de la rambla de la dita ciutat, per donar bon principi al dit Studi. Considerant que del bon assento de aquell ne resultaran moltes comoditats e utilitats per als poblats en la dita ciutat, així en lo espiritual, ço és, que per medi de la sciència los ànimos d'ells seran ben assentats e instruïts al camí verdader de la glòria, per la qual lo home és creat, extirpants los vicis e seguints les virtuts, y encara per a ben aconsellar, regir y governar la república de la present ciutat quan los serà comanada, com encara en lo temporal per l'augment dels drets de aquella resultant de la confluència dels studiants, qui no sols del present Principat més encara dels regnes propinqües vindran en gran nombre a studiar y apendre les bones lletres en lo dit Studi, com s'és vist ja per la experiència, que per haver estipendiats en los anys passats bons preceptors és crescut en bona summa lo número dels studiants en lo dit Studi. E serà encara donar remey als poblats de la present ciutat que, desitjant tenir sos fills doctes, los enviaven fora de la present ciutat en parts longniques ab gran dispendi de llurs substàncies y perills de les persones de aquells. ${ }^{26}$
\end{abstract}

Unos objetivos tan ambiciosos no podía conseguirse sin un incremento de la financiación, que el ayuntamiento evaluó en 860 libras. Tal cifra resultaba de la suma de la asignación municipal -incrementada ahora a 340 libras-, las aportaciones del obispo y cabildo que habían prometido

24AHCB, Estudi General, XVIII- 9, doc. s. n.

25 AHCB, Registre de deliberacions, II-57, p. 77.

26 AHCB, Registre de crides i ordinacions, IV-16, p. 121.

SCRIPTA, Revista internacional de literatura i cultura medieval i moderna, núm. 15 / juny 2020 / pp. 172 - 186 
invertir 120 libras y los pagos de los estudiantes que representarían unas 400 libras. La colaboración financiera de la Iglesia supuso la creación de nuevos oficiales económicos, los denominados administradores del Estudio, que se encargaban de la cobranza y administración de los ingresos y del pago de los salarios de los catedráticos y oficiales. Esta junta económica, elegida cada dos años, estaba integrada por dos representantes de la ciudad y otros dos del estamento eclesiástico. ${ }^{27}$

La selección del profesorado también era compartida por los representantes municipales y los del clero local. En lo sucesivo, la realizarían los consellers en cap, quart y quint, el obispo de Barcelona o su vicario general, un canónigo elegido por el capítulo de la catedral, el pavorde de Valencia Onofre Gualbes y el Primario del Estudio. Como los consellers se renovaban anualmente, fueron los clérigos quienes más influyeron tanto en la administración como en la configuración del cuadro profesoral, durante el período que discurre entre 1544 y 1559. Se trataba de personajes como Francesc Solsona, Onofre Gualbes, Guillem Cassador y Damià Hortolà, cuya influencia fue decisiva a la hora de decidir la orientación ideológica de los saberes y su apertura a las nuevas corrientes del pensamiento humanista y del erasmismo.

El pavorde Onofre Gualbes fue poeta y amigo de Juan Boscán. El vicario general Francesc Solsona protegió a Juan de Mal Lara cuando dejó los estudios de humanidades que cursaba en Salamanca para acudir a Barcelona con objeto de seguir las enseñanzas erasmistas de Francesc Escobar. Guillem Cassador, doctor en derecho canónico, abad de Sant Feliu de Girona y canónigo de Barcelona, muy vinculado al Santo Oficio, acabaría siendo obispo de la ciudad a partir de 1561. Durante el ejercicio de sus funciones como Primario del Estudio, Damià Hortolà, erudito de saber enciclopédico y teólogo sobresaliente por sus estudios bíblicos, sería la figura clave de la nueva orientación académica y el principal promotor de la expansión universitaria en estos años.

Durante la primera mitad del siglo xvi, el Estudio de las Artes liberales de Barcelona se caracterizó por su apertura a las corrientes más innovadores del pensamiento europeo, como el humanismo, el erasmismo y la lógica renacentista. La contratación, a cambio de elevados salarios, de reputados profesores dio al Estudio de Artes un prestigio superior al que, por sus dimensiones, cabía esperar. Martín Ibarra, estrechamente vinculado al mundo editorial barcelonés y amigo de Miquel Mai, vicecanciller de la Corona de Aragón, y del arcediano Lluís Desplà, tuvo estrecha relación con la aristocracia barcelonesa y con el pequeño círculo erasmista local. Introdujo los nuevos métodos pedagógicos de Nebrija y escribió una notable obra literaria y poética en latín. Ibarra, junto con Jeroni Ardèvol, el maestro de Ignacio de Loyola en Barcelona, Cosme Mestre y otros latinistas arrinconó las gramáticas medievales y creó una Escuela de Humanidades (1532) cuyo plan de estudios -en el que se entreveraba un amplio ramillete de autores clásicos con humanistas del fuste de Lorenzo Valla o Tomás Linacro- era de los más avanzados del momento. Rafael Mambla y el mercedario valenciano Narcís Gregori introdujeron la lógica renacentista, y el retórico Francesc Escobar editó para su uso escolar la gramática y los Coloquios de Erasmo.

27 AHCB, Registre de crides i ordinacions, IV-16, p. 122. 
El crecimiento del Estudio de las Artes liberales, que había ido ampliado sus enseñanzas con la introducción de algunas cátedras de teología, derecho y medicina a mediados del siglo xvI, constituyó una sólida plataforma para la definitiva creación de la universidad que, dependiente del municipio, fue instituida el 22 de septiembre de 1559. En esa fecha, después de diversos coloquios con el obispo, el cabildo y la congregación eclesiástica de Barcelona, los consellers promulgaron unas nuevas ordenanzas per reformació y perpètua fundació de la Universitat del Studi General. ${ }^{28}$ Para ello, invocaron el privilegio fundacional de Alfonso el Magnánimo y la bula pontificia de Nicolás V, omitiendo que esta había sido derogada a instancias de la Universidad de Lérida, y se arrogaron el derecho de patronazgo sobre el centro educativo, promulgando los reglamentos y designando a los catedráticos.

28 Ordinacions per reformació y pertpetua fundació de la Universitat del Studi General de la ciutat de Barcelona (1559), publicadas en 1560, por Jaume Cortey. 


\section{Fuentes}

$\mathrm{AHCB}=$ Archivo Histórico de la Ciudad de Barcelona.

-Registre de crides i ordinacions, IV-12; IV-16.

—Registre de deliberacions, II-39; II-52; II-53; II-54; II-55.

-Estudi General, serie XVIII, vol. 9, docs. 14, 17, 20.

$\mathrm{AHPB}=$ Archivo Histórico de Protocolos de Barcelona.

-Liber Studii Generalis medicorum et artistarum civitatis Barchinone, 1534-1559, notario Joan Lunes, 6, legajo 304.

Dietari= Dietari del Antich Consell Barceloní, Barcelona, 1894, vol. III.

Documentos $=$ Documentos para la historia de la Universidad de Barcelona. I. Preliminares (1289-1451). Antonio de la Torre y del Cerro. Barcelona, Ediciones de la Universidad de Barcelona, 1971.

\section{Bibliografía}

Álvarez de Morales, A. (1987) «La Universidad y sus denominaciones», dentro VV. AA, Universidades españolas y americanas. Época colonial, CSIC, Valencia, pp. 57-65.

Balari i Jubany, José (1897) Historia de la Universidad de Barcelona, Barcelona, Annuari de la Universitat de Barcelona (1896-97).

Batlle i Prats, Lluís (1947) «Estudiantes gerundenses en los Estudios Generales», Hispania, 27, p. 197-220.

Carrere, Claude (1967) Barcelone, centre économique à l'époque des difficultés, 1380-1462, París, Éditions de l'École des Hautes Études.

—. (1979) «Refus d'une création universitaire et niveaux de culture à Barcelone: hypothèses d'explication», Le Moyen Age, 85, p. 245-273.

De la Torre y del Cerro, Antonio (1929) Reseña histórica y guía descriptiva de la Universidad, Barcelona, Impresor J. Horta.

Dulieu, Louis (1971) «Le Collège de Girone de Montpellien», Actes del Primer Congrés Internacional d'Història de la Medicina Catalana, IV, p. 89-105.

Fernández Luzón, Antonio (2005), La Universidad de Barcelona en el siglo XVI, Publicacions i edicions de la Universitat de Barcelona.

SCRIPTA, Revista internacional de literatura i cultura medieval i moderna, núm. 15 / juny 2020 / pp. 172 - 186 
Gaya Massot, Ramón (1952) «Las rentas del Estudio General de Lleida», Analecta Sacra Tarraconensia (AST), XXV (1952), p. 293-338.

. (1952a) «Por qué se retardó la fundación de la Universidad de Barcelona», Analecta Sacra Tarraconensia (AST), XXV, p. 165-171.

Oriol Montagut, Ana María (1959), La enseñanza en Barcelona a fines del siglo XVIII, Madrid, CSIC, Instituto «San José de Calasanz» de Pedagogía.

Ordinacions per reformació y pertpetua fundació de la Universitat del Studi General de la ciutat de Barcelona (1560), Barcelona, Jaume Cortey.

Ridder-Symoens, H. (ed.) (1994), Historia de la Universidad en Europa, vol. I: Las Universidades en la Edad Media, Servicio Editorial Universidad del País Vasco, Bilbao.

Sanabre, José (1960), Alfonso el Magnánimo, promotor de la fundación de la Universidad de Barcelona, Barcelona, Universidad de Barcelona.

Valls Taberner, Fernando (1915) Los abogados de Cataluña durante la Edad Media, Barcelona, Imprenta de Altis Alabart. 